\title{
Preoperative statin is associated with decreased operative mortality in high risk coronary artery bypass patients
}

James A Magovern, Robert J Moraca*, Stephen H Bailey, David A Dean, Kathleen A Simpson, Thomas D Maher, Daniel H Benckart, George J Magovern Jr

\begin{abstract}
Background: Statins are widely prescribed to patients with atherosclerosis. A retrospective database analysis was used to examine the role of preoperative statin use in hospital mortality, for patients undergoing isolated coronary artery bypass grafting (CABG.)

Methods: The study population comprised 2377 patients who had isolated CABG at Allegheny General Hospital between 2000 and 2004. Mean age of the patients was $65 \pm 11$ years (range 27 to 92 years). 1594 (67\%) were male, 5\% had previous open heart procedures, and 4\% had emergency surgery. 1004 patients (42\%) were being treated with a statin at the time of admission. Univariate, bivariate (Chi ${ }^{2}$, Fisher's Exact and Student's t-tests) and multivariate (stepwise linear regression) analyses were used to evaluate the association of statin use with mortality following $C A B G$.
\end{abstract}

Results: Annual prevalence of preoperative statin use was similar over the study period and averaged $40 \%$. Preoperative clinical risk assessment demonstrated a $2 \%$ risk of mortality in both the statin and non-statin groups. Operative mortality was $2.4 \%$ for all patients, $1.7 \%$ for statin users and $2.8 \%$ for non-statin users ( $p<0.07$ ). Using multivariate analysis, lack of statin use was found to be an independent predictor of mortality in high-risk patients ( $n=245,12.9 \%$ vs. $5.6 \%, p<0.05$ ).

Conclusions: Between 2000 and 2004 less than $50 \%$ of patients at this institution were receiving statins before admission for isolated CABG. A retrospective analysis of this cohort provides evidence that preoperative statin use is associated with lower operative mortality in high-risk patients.

\section{Introduction}

The use of 3-hydroxy-3-methyl-glutaryl coenzyme A reductase inhibitors (statins) has been shown to reduce death, myocardial infarction and stroke in patients with elevated serum cholesterol and in those with near normal serum cholesterol levels [1]. The mechanism of this improvement is likely multifactorial, with some benefit attributed to lipid lowering effects and some to lipidindependent (pleiotropic) properties. Recently, evidence has accumulated that statins have beneficial effects on various portions of the clinical pathway that leads to atherosclerosis and cardiovascular events. These effects

\footnotetext{
* Correspondence: rmoraca@wpahs.org

Department of Cardiovascular and Thoracic Surgery, Allegheny General Hospital, Pittsburgh, PA, USA
}

include downregulation of the inflammatory cascade [2], stabilization of the endothelial cell [3], attenuation of oxidative damage [4], decreasing thrombotic risk and possibly plaque stabilization [5]. The use of statins has steadily increased over time, but these drugs remain under utilized, relative to the larger population at risk for atherosclerosis. Patients who require coronary artery bypass grafting (CABG) represent a small segment of the entire population of patients with coronary artery disease. Many CABG patients have been treated with statins as outpatients before CABG, but a sizeable group present with no previous statin therapy. This study was undertaken to examine the efficacy of preoperative statin use on in-hospital mortality after CABG surgery.

\section{Biomed Central}




\section{Patients and Methods Data Collection}

Data were retrospectively abstracted from the institution's cardiac surgery database, which includes over 500 variables describing patient history, pre-, intra- and post-operative data and events and selected laboratory and functional testing results. Data from every patient who undergoes a major cardiac procedure is recorded on a standardized form and entered into the database by trained database staff during the admission and immediately following discharge. Data is collected under a waiver of consent from the Allegheny General Institutional Review Board.

\section{AGH Clinical Risk Score}

As part of surgical consultation all patients are assigned a numerical clinical risk score (CRS) based on preoperative variables, including factors such as age, left ventricular function, comorbid diseases and laboratory studies. The risk score model is validated and has been described fully in a previous publication [6]. A recent study has confirmed the efficacy of the Magovern CRS in comparison to other well known risk assessment models [7]. The CRS ranges between 0 and 20 with a lower score predicting lower operative mortality. In this study, high risk patients were defined as those with a CRS of 9 or above (predicted mortality of at least 6\%). Major postoperative morbidity was defined as the occurrence of any of the following complications: inotrope use for greater than 24 hours, acute myocardial infarction, cerebrovascular accident, respiratory failure, new onset renal failure, deep sternal wound infection or reoperation for bleeding/tamponade.

\section{Operative Technique}

Standard anesthesia and surgical techniques were utilized for all patients. Based upon preoperative beliefs and pathology, patients were offered conventional cardiopulmonary bypass or when appropriate; an off pump technique. Conventional cardiopulmonary bypass utilized systemic heparinization (300 $\mathrm{mg} / \mathrm{kg}$ heparin sulfate) to maintain an activated clotting time (ACT) $>450$ seconds. Off pump cardiac surgery utilized $100 \mathrm{mg} / \mathrm{kg}$ loading dose of heparin with a goal to maintain an ACT $>300$ seconds. Moderate hypothermia 34 Celsius was used in all cardiopulmonary bypass operations and patients were re-warmed to 36 Celsius prior to discontinuing the cardiopulmonary bypass. Cold blood cardioplegia was utilized for induction and maintenance.

\section{Patient Population}

The study population comprised all patients who underwent isolated CABG surgery between January 1, 2000 and December 31, 2004. This study period was chosen because it afforded a large, comparable cohort of patients in both the statin and non-statin treated groups. Patients were considered to be in the "statin" group if they were taking statins at the time of admission or they were started during the admission prior to surgery. No data regarding the specific drug or dose was obtained.

\section{Statistical Analysis}

Data are expressed as mean \pm standard deviation (continuous variables) or incidence and percent of the relevant group. The study endpoint was defined as all cause in-hospital mortality. Bivariate analyses were performed to examine associations between preoperative status variables and this endpoint, using Student's t-test, Mann-Whitney rank sums test, Chi-square analysis and Fisher's exact test, as appropriate for continuous and dichotomous variables. Variables with significant $(\mathrm{p}<$ 0.15 ) bivariate evidence of association with the endpoint were then evaluated using stepwise logistic regression to determine which of the variables contributed to a multivariate prediction model for in-hospital mortality. BMDP Statistical Software, release 7 was used to perform all analyses.

\section{Results}

Both the proportion of preoperative statin usage and the predicted mortality score for coronary bypass patients were similar over the course of the study period (Table 1 ). Table 2 illustrates the prevalence of relevant pre- and intra-operative variables in the overall population and in the statin and no statin study groups. There was no difference in incidence of any major preoperative co-morbidity. Mean left ventricular ejection fraction (LVEF) was 47.4 \pm 13.8 in the no-statin group and $48.6 \pm 13.6$ in the statin group. Distribution of LVEF values (0-19\%, 20-29\%, 30$39 \%, 40-49 \%, 50 \%$ and higher) was also similar. The nostatin group was statistically older from the statin group (65.4 vs. 64.8, $\mathrm{p}=0.02$ ), however this difference has negligible clinical relevance.

Table 1 Preoperative statin usage and clinical risk score in CABG patients by year of surgery

\begin{tabular}{lccccc}
\hline Year: & $\mathbf{2 0 0 0}$ & $\mathbf{2 0 0 1}$ & $\mathbf{2 0 0 2}$ & $\mathbf{2 0 0 3}$ & $\mathbf{2 0 0 4}$ \\
\hline Statin Usage (\%) & $246 / 647(38 \%)$ & $220 / 523(42 \%)$ & $204 / 447(46 \%)$ & $181 / 423(43 \%)$ & $153 / 337(45 \%)$ \\
Mean CRS & $4.6 \pm 3.7$ & $4.5 \pm 3.2$ & $4.7 \pm 3.7$ & $4.0 \pm 3.0$ & $4.5 \pm 3.2$ \\
\hline
\end{tabular}

CRS: Allegheny General Hospital cardiac surgery clinical risk score. 
Table 2 Study Population and results of bnivariate analysis of statin groups

\begin{tabular}{|c|c|c|c|}
\hline & All & Statin & No Statin \\
\hline Patients & 2377 & 1004 & 1373 \\
\hline Age (years) & $65.4 \pm 10.7$ & $64.8 \pm 10.9$ & $65.8 \pm 10.3^{\mathrm{a}}$ \\
\hline Off-Pump CABG & $321(13.4 \%)$ & $167(6.9 \%)$ & $154(6.4 \%)$ \\
\hline CAB Grafts & $2.9 \pm 1.0$ & $2.8 \pm 1.0$ & $2.9 \pm 1.1$ \\
\hline AXC (minutes) & $72.4 \pm 25.1$ & $73.0 \pm 25.3$ & $71.9 \pm 24.9$ \\
\hline CPB (minutes) & $103 \pm 33$ & $104 \pm 33$ & $102 \pm 32$ \\
\hline Non-elective procedure & 1376 (57\%) & $568(57 \%)$ & $808(59 \%)$ \\
\hline Redo Procedure & $125(5.3 \%)$ & $66(6.6 \%)$ & $59(4.3 \%)^{b}$ \\
\hline Female gender & 719 (30.2\%) & $298(29.7 \%)$ & $421(30.7 \%)$ \\
\hline Congestive heart failure history & $316(13.3 \%)$ & $133(13.2 \%)$ & $183(13.3 \%)$ \\
\hline Cardiomegaly & $94(4.0 \%)$ & $41(4.1 \%)$ & $53(3.9 \%)$ \\
\hline Atrial arrhythmia history & $133(5.6 \%)$ & $43(4.3 \%)$ & $87(6.3 \%)$ \\
\hline Body mass index $<25$ & 340 (14.3\%) & $132(13.1 \%)$ & $208(15.1 \%)$ \\
\hline Preoperative AMI & $428(18.0 \%)$ & $167(16.6 \%)$ & $261(19.0 \%)$ \\
\hline COPD & 402 (16.9\%) & $184(18.3 \%)$ & $218(15.9 \%)$ \\
\hline Peripheral vascular disease & $340(14.3 \%)$ & $144(14.3 \%)$ & $196(14.3 \%)$ \\
\hline Stroke history & $144(6.1 \%)$ & $56(5.6 \%)$ & $88(6.4 \%)$ \\
\hline Renal failure & 77 (3.2\%) & $28(2.8 \%)$ & $49(3.6 \%)$ \\
\hline Tobacco past/current & $1101(46.3 \%)$ & 499 (49.7\%) & $602(43.8 \%)$ \\
\hline IDDM & $260(10.9 \%)$ & $124(12.4 \%)$ & $136(9.9 \%)$ \\
\hline In-hospital death & $56(2.4 \%)$ & $17(1.7 \%)$ & $39(2.8 \%)^{c}$ \\
\hline
\end{tabular}

AMl: acute myocardial infarction, a: $p=0.02 ; \mathrm{b}: p=0.01 ; \mathrm{c}: p=0.07$.

Patients undergoing a redo open heart procedure were more likely to be receiving statin treatment, likely reflecting more focused cardiac care following the previous surgery. Surgical indices of grafts performed, and cross-clamp and cardiopulmonary bypass times did not differ between groups. 13.4\% of patients underwent offpump CABG, with no difference noted between the statin and non-statin groups. There were no differences regarding intubation time, ICU duration and hospital stay. The results of bivariate analysis between mortality rate and relevant preoperative variables are shown in Table 3. Each of these variables, with the exception of non-insulin diabetes mellitus, was used for the multivariate assessment. Multivariate analysis was used to determine which variables were independently associated with decreased mortality in the study population. Variables with a significant independent contribution to mortality risk are illustrated in Table 4 . When considering the entire population there was no significant contribution of statins to operative risk. However the absence of statin treatment was associated with an increase in mortality in the subset of high risk patients with an estimated risk of mortality of $6 \%$ and greater.

Multivariate regression analysis was also performed using composite postoperative major morbidity as an endpoint. Statin usage was not shown to have a significant impact on composite major morbidity in this limited assessment.

\section{Discussion}

Statins are one of the most effective medicines introduced in the past 25 years. Nonetheless they are still relatively under prescribed, especially in patients without symptomatic or obvious atherosclerosis and those without severe hypercholesterolemia. Recently, our knowledge regarding the biology of the non-lipid lowering, or pleiotropic effects of statins has rapidly expanded. Simultaneously, a number of recent reports have suggested a salutary effect of statins on perioperative mortality for patients undergoing CABG.

Clark, et al, reported a retrospective database study from the Medical University of South Carolina covering 3829 patients between 1996 and 2002 [8]. Only 1044/ 3829 patients received preoperative therapy (28\%). In a propensity matched analysis they demonstrated significant association between preoperative statin therapy and lower 30 day mortality and morbidity. These findings paralleled those of an earlier study by Pan et al from the Texas Heart Institute [9]. This study evaluated 1563 patients who underwent $C A B G$ with $C P B$ at a single institution. Multivariate analysis was used to show a $50 \%$ reduction in the risk of perioperative (30 day) death in those patients who received statins preoperatively. The use of statins preoperatively was not associated with a lower incidence of post-operative complications. In a propensity matched subgroup analysis statin therapy was associated with a significantly lower risk of the composite endpoint including death and stroke (but not death alone).

Collard, et al, showed similar results in a large international, multi-institutional study [10]. The primary study was a longitudinal analysis of 5436 patients at 70 centers undergoing CABG. The statin study was a posthoc retrospective analysis using this database and showed reduced early cardiac mortality in patients receiving statins who underwent elective CABG $(0.3 \%$ vs. $1.4 \%)$. Further, the discontinuation of statins postoperatively was associated with increased all-cause hospital mortality ( $2.6 \%$ vs. $0.6 \%)$ compared to those who had statin therapy maintained.

Statin use in the current study averaged $42 \%$ (range 38 - 46\%) over the five-year period of 2000-2004. The relatively low prevalence may represent a referral bias in that our center is a primary angioplasty referral center. Consequently, many patients have a new diagnosis of coronary artery disease and the statin is not always started before operation, especially in the urgent or 
Table 3 Results of bnivariate analysis of mortality rates associated with selected preoperative variables

\begin{tabular}{|c|c|c|c|}
\hline Variable: & Present & Not Present & $p$ value \\
\hline Preoperative statin & $17 / 1004(1.7 \%)$ & $39 / 1373(2.8 \%)$ & 0.07 \\
\hline Preoperative AMI & 19/428 (4.4\%) & $37 / 1949(1.9 \%)$ & 0.002 \\
\hline Preoperative anemia & 18/437 (4.1\%) & $38 / 1940(2.0 \%)$ & 0.007 \\
\hline Body mass index $<25$ & $14 / 340(4.1 \%)$ & $42 / 2037(2.1 \%)$ & 0.02 \\
\hline Non insulin dependent diabetes & $10 / 500(2.0 \%)$ & $46 / 1877(2.5 \%)$ & 0.55 \\
\hline Insulin dependent diabetes & $14 / 260(5.4 \%)$ & $42 / 2117(2.0 \%)$ & 0.006 \\
\hline Chronic obstructive pulmonary disease & $16 / 402(4.0 \%)$ & $40 / 1975(2.0 \%)$ & 0.02 \\
\hline Stroke history & $6 / 144(4.2 \%)$ & $50 / 2233(2.2 \%)$ & 0.14 \\
\hline Peripheral vascular disease & $12 / 340(3.5 \%)$ & $44 / 2037(2.2 \%)$ & 0.12 \\
\hline Renal failure history & $5 / 77(6.5 \%)$ & $51 / 2300(2.2 \%)$ & 0.02 \\
\hline Atrial arrhythmia history & 14/133 (10.5\%) & $42 / 2244(1.9 \%)$ & $<0.001$ \\
\hline Congestive heart failure history & $21 / 316(6.7 \%)$ & $35 / 2061(1.7 \%)$ & $<0.001$ \\
\hline Tobacco past/current & 33/1101 (3.0\%) & $23 / 1276(1.8 \%)$ & 0.06 \\
\hline Female gender & 25/719 (3.5\%) & $31 / 1658(1.9 \%)$ & 0.02 \\
\hline Cardiomegaly & 8/94 (8.5\%) & 48/2283 (2.1\%) & $<0.001$ \\
\hline \multirow[t]{2}{*}{ Redo procedure } & $9 / 125(7.2 \%)$ & $47 / 2252(2.1 \%)$ & $<0.001$ \\
\hline & Survivors & In-hospital death & \\
\hline Age (years) & $65.3 \pm 10.7$ & $71.5 \pm 8.9$ & $<0.001$ \\
\hline
\end{tabular}

AMI: acute myocardial infarction.

Table 4 Preoperative variables identified as independent predictors of in-hospital mortality following CABG surgery

\begin{tabular}{lcc}
\hline & Coefficient & $\boldsymbol{p}$ value \\
\hline All Patients & & \\
Atrial arrhythmia history & 0.84 & $<0.001$ \\
Congestive heart failure history & 0.87 & $<0.001$ \\
Age (years) & 0.06 & $<0.001$ \\
Redo procedure & 1.20 & 0.009 \\
Preoperative AMl & 0.84 & 0.005 \\
Insulin dependent diabetes & 0.85 & 0.009 \\
Tobacco past/current & 0.77 & 0.024 \\
Female gender & 0.56 & 0.066 \\
High Risk Patients & & \\
Insulin dependent diabetes & 1.10 & 0.070 \\
Preoperative statin use & -1.07 & 0.030 \\
\hline
\end{tabular}

AMl: acute myocardial infarction.

emergent situation. Beginning in 2005 our isolated CABG population demonstrated an increase in preoperative statin use to greater than $80 \%$.

The most important objective of this study was to determine if the use of preoperative statin therapy is associated with reduced postoperative mortality. In each of the 5-years of the study, the mortality rate was lower in the group of patients exposed to statins preoperatively (range $26-60 \%$.) In total, the net effect was to reduce mortality from $2.8 \%$ to $1.7 \%$. The effect was seen in all groups, but was most notable in the high risk cohort $(12.9 \%$ vs. $5.6 \%, \mathrm{p}<0.05)$, where the predicted mortality was $6 \%$ and higher.
This study was not designed to explain how statins exert their salutary effect. Nonetheless, a number of hypotheses are generated. Our group [11] and others [12] have recently shown that patients undergoing heart surgery who have elevated risk based on standard preoperative variables (age, left ventricular dysfunction, comorbid disease) have evidence of ongoing inflammation manifested by elevated levels of inflammatory mediators such as interleukin-6 (IL-6) and C-reactive protein (CRP). Statins have been shown to ameliorate the inflammatory cascade in a number of models and these properties may confer protection from the inflammatory response induced by open heart surgery. This may explain the more pronounced protective effect of statins in our high risk cohort.

Statins have also been shown in clinical trials to be associated with decreased mortality when administered in the first 24 hours after acute myocardial infarction $[13,14]$. This may be the result of their potential ability to limit infarct size, as demonstrated in animal models of acute infarction [15]. These properties may contribute to the beneficial effect associated with CABG and would help to explain the more marked effect in high risk patients, many of whom require urgent or emergent surgery in the setting of acute ischemia or infarction.

The current study, in addition to all the other studies on preoperative statin use, is retrospective and nonrandomized. This introduces the issue of selection bias and other confounding variables. The statistical analysis minimizes this possibility, but it cannot eliminate this issue completely. Further, we do not have specific 
information regarding the specific statin, dose, duration or cholesterol lowering efficacy. There may be important factors with regard to dosage and duration of therapy that impact the benefit of statins in this patient population that we can not identify with this study. Nonetheless, we have shown a consistent reduction in perioperative mortality in patients being treated with statins, particularly those with elevated operative risk. While placebo controlled trials will likely not be possible, further study of the underlying mechanisms of these effects are needed.

\section{Acknowledgements}

Presented at the $43^{\text {rd }}$ Annual Meeting of the Society of Thoracic Surgery, San Diego, CA, January 30, 2007.

\section{Authors' contributions}

JAM performed the initial study design and oversight of the manuscript preparation. RJM contributed to the statistical analysis, designed and wrote the tables and performed all the major and minor revisions of the manuscript. SAB assisted in study design, manuscript preparation, and presentation at national meeting. DAD assisted in study design and statistical analysis. KAS developed the database and performed statistical analysis. DHB assisted in study design and manuscript preparation. TDM assisted in manuscript preparation, initial data analysis and study design. GJM Jr. performed the initial study design and authored key sections of the manuscript. All authors read and approved the final manuscript.

\section{Competing interests}

The authors declare that they have no competing interests.

Received: 1 November 2009

Accepted: 24 February 2010 Published: 24 February 2010

\section{References}

1. Third Report on the National Cholesterol Education Program (NCEP) Expert Panel on Detection, Evaluation, and Treatment of High Blood Cholesterol in Adults (Adult Treatment Panel III) final report. Circulation 2002, 06:3143-3421.

2. Kinlay S, Egido J: Inflammatory biomarkers in stable atherosclerosis. Am J Cardiol 2006, 98(11A):2P-8P.

3. Walter DH, Rittig K, Bahlmann FH, Kirchmair R, Silver M, Murayama T, Nishimura H, Losordo DW, Asahara T, Isner JM: Statin therapy accelerates re-endothelialization: a novel effect involving mobilization and incorporation of bone marrow-derived endothelial progenitor cells. Circulation 2002, 105:3017-3024.

4. Sotirios T: Oxidative biomarkers in the diagnosis and prognosis of cardiovascular disease. Am J Cardio/ 2006, 98(11A):9P-17P

5. Libby $P$, Sasiela W: Plaque stabilization: can we turn theory into evidence?. Am J Cardiol 2006, 98(11A):26P-33P.

6. Magovern JA, Sakert T, Magovern GJ, Benckart DH, Burkholder JA, Liebler GA, Magovern GJ Sr: A model that predicts morbidity and mortality after coronary artery bypass graft surgery. J Am Coll Cardiol 1996, 28(5):1147-53.

7. Nilsson J, Algotsson L, Höglund P, Lührs C, Brandt J: Comparison of 19 pre-operative risk stratification models in open heart surgery. Eur Heart $J$ 2006, 27:867-874.

8. Clark LL, Ikonomidis JS, Crawford FA Jr, Crumbley A, Kratz JM, Stroud MR, Woolson RF, Bruce JJ, Nicholas JS, Lackland DT, Zile MR, Spinale FG: Preoperative statin treatment is associated with reduced postoperative mortality and morbidity in patients undergoing cardiac surgery: an 8year retrospective cohort study. J Thorac Cardiovasc Surg 2006, 131:679-85.

9. Pan W, Pintar T, Anton J, Lee W, Vaughn WK, Collard CD: Statins are associated with a reduced incidence of perioperative mortality after coronary artery bypass graft surgery. Circulation 2004, 110:||-45-||-49.
10. Collard CD, Body SC, Shernan SK, Wang S, Mangano DT: Preoperative statin therapy is associated with reduced cardiac mortality after coronary artery bypass graft surgery. J Thorac Cardiovasc Surg 2006 132:392-400

11. Magovern JA, Singh D, Teekell-Taylor L, Scalise D, McGregor W: Preoperative clinical factors are important determinants of the inflammatory state before and after heart surgery. ASAIO J 2007, 53(3):316-9.

12. Podgoreanu MV, White WD, Morris RW, Mathew JP, Stafford-Smith M, Welsby IJ, Grocott HP, Milano CA, Newman MF, Schwinn DA: Inflammatory gene polymorphisms and risk of postoperative myocardial infarction after cardiac surgery. Circulation 2006, 114(1 Suppl):I275-I281.

13. Wright RS, Bybee K, Miller WL, Laudon DA, Murphy JG, Jaffe ASI: Reduced risks of death and CHF are associated with statin therapy administered acutely within the first 24 hours of AMI. Int J Cardiol 2006, 108:314-319.

14. Ray KK, Cannon CP, Ganz P: Beyond lipid lowering: what have we learned about statins from the acute coronary syndrome trials. Am J Cardiol 2006, 98(11A):18P-25P

15. Tiefenbacher CP, Kapitza J, Dietz V, Lee CH, Niroomand F: Reduction of myocardial infarct size by fluvastatin. Am J Physiol Heart Circ Physiol 2003, 285:H59-64.

doi:10.1186/1749-8090-5-8

Cite this article as: Magovern et al:: Preoperative statin is associated with decreased operative mortality in high risk coronary artery bypass patients. Journal of Cardiothoracic Surgery 2010 5:8.

\section{Submit your next manuscript to BioMed Central and take full advantage of:}

- Convenient online submission

- Thorough peer review

- No space constraints or color figure charges

- Immediate publication on acceptance

- Inclusion in PubMed, CAS, Scopus and Google Scholar

- Research which is freely available for redistribution

Submit your manuscript at www.biomedcentral.com/submit
C Biomed Central 